DOI 10.37882/2500-3682.2020.10.09

\title{
ОСОБЕННОСТИ ВОЛЕВОЙ РЕГУЛЯЦИИ СТУДЕНТОВ В ПРОЦЕССЕ АДАПТАЦИИ К ИНОКУЛЬТУРНОЙ СРЕДЕ
}

\section{SPECIFIC FEATURES OF THE VOLITIONAL REGULATION IN THE PROCESS \\ OF FOREIGN STUDETS' ADAPTATION \\ TO THE CROSS-CULTURAL ENVIRONMENT \\ A. Kuts \\ K. Vorobieva}

Summary: The article presents the results of an empirical study in the field of specific features of the volitional regulation in the process of foreign students' adaptation to the cross-cultural environment. A hypothesis is put forward about the relationship between the level of development of indicators of the volitional regulation and the success of the process of adaptation to a new socio-cultural and educational environment.

The study involved 250 foreign students of Penza State University (ethnic community - Arabs; age structure of respondents: from 17 to 24 years old, average age - 20.1; gender of the respondents: men $-n=125$, women $-n$ $=125$ ).

In the current research there was used a set of diagnostic methods such as: "Questionnaire for identifying the severity of self-control in the emotional sphere, activity and behavior» (G.S. Nikiforov), «Action control scale» (Yu. Kuhl); "Formalized modification of the self-assessment method (SA)" (Dembo-Rubinstein); "Test of meaningful life orientations" (D.A. Leontiev); a questionnaire concerning a number of demographic characteristics of respondents and an assessment of the level of satisfaction with new conditions in the cross-cultural environment (climate, culture, food, living conditions, education, leisure, etc.).

It has been found that the success of the adaptation process of foreign students to the cross- cultural environment is interconnected with a number of indicators of the volitional regulation: OD-disposition of the personality, social self-control, meaningfulness of life goals and a certain set of volitional qualities.

The applied aspect of the problem could be integrated in the development of well-timed aid to build a system of socio-psychological support and to support the individuals in situations of social or life changes.

Keywords: adaptation, volitional regulation, volitional qualities, selfcontrol, foreign students, cross-cultural environment.
Куц Анна Вячеславовна

К.п.н., дочент, Пензенский государственный университет

kuts_a.v@mail.ru

Воробьева Кристина Игоревна

Пензенский государственный университет

v.i.e.3@mail.ru

Аннотация: В статье приводятся результаты эмпирического исследования особенностей волевой регуляции студентов в процессе адаптации к инокультурной среде. Выдвигается гипотеза о взаимосвязи уровня развития показателей волевой регуляции и успешности протекания процесса адаптации $\mathrm{k}$ новой социокультурной и образовательной среде.

В исследовании приняли участие 250 иностранных студентов Пензенского государственного университета (этническая общность - арабы; возрастная структура респондентов: от 17 до 24 лет, средний возраст - 20,1; гендерный состав респондентов: муж. $-n=125$, жен. $-n=125$ ).

Для исследования особенностей волевой регуляции иностранных студентов применялся комплекс диагностических методик: «Вопросник для выявления выраженности самоконтроля в эмоциональной сфере, деятельности и поведении» (Г.С. Никифоров), «Шкала контроля за действием» (Ю. Куль); «Формализованная модификация методики самооценки (СО)» (Дембо-Рубинштейн); «Тест смысложизненных ориентаций» (Д.А. Леонтьев); опросник касающийся ряда демографических характеристик респондентов и оценки уровня удовлетворённости условиями пребывания в инокультурной среде (климат, культура, питание, условия проживания, обучения, досуг и т.п.).

Установлено, что успешность процесса адаптации студентов к инокультурной среде взаимосвязана с рядом показателей волевой регуляции: ОДдиспозицией личности, социальным самоконтролем, осмысленностью жизненных целей и определенным набором волевых качеств.

Прикладной аспект исследуемой проблемы может быть реализован в разработке средств оперативной помощи, для построения системы социальнопсихологической поддержки и сопровождения личности в ситуации социальных или жизненных изменений.

Ключевые слова: адаптация, волевая регуляция, волевые качества, самоконтроль, иностранные студенты, инокультурная среда.

\section{Введение}

$\mathrm{B}$ последнее время в психологической науке была организована серия эмпирических исследований, подтверждающих особое значение волевой регуляции в достижении поставленных целей, в профессиональной, спортивной, учебной и иных видах деятельности (Барабанов Д.Д., Быков А.В., Иванников В.А., Леонтьев Д.А., Монроз А.В., Шляпников В.Н., Шульга Т.И. и др.). Однако вопрос об особенностях волевой регуляции 
в процессе адаптации к инокультурной среде остается открытым для научного поиска. Большая часть исследований отечественной психологии базируется на представлении воли как высшей психической функции (ВПФ), регулирующей поведение и психические процессы личности $[2 ; 3 ; 4 ; 5 ; 9]$.

Современные психологи-исследователи отмечают, что источником развития волевой регуляции как ВПФ выступает культура как устойчивый общественно-исторический образ жизни, предписывающий его носителю набор традиционных ценностей, определенных видов деятельности, способов их реализации, которые индивид усваивает в процессе социализации в согласии со своим уникальным смысловым опытом [1; 3; 7].

Обучение в высшей школе предъявляет высокие требования к волевой регуляции личности, так как существенно возрастает уровень учебной нагрузки, изменяются требования к дисциплинированности, самостоятельности и персональной ответственности, происходит изменение привычного круга общения, смена ценностных ориентаций. Иностранные студенты помимо необходимости решения новых задач в процессе овладения учебно-профессиональной деятельностью испытывают трудности в приспособлении к инокультурной среде, именно поэтому на первых курсах обучения наблюдается наиболее интенсивное развитие большинства показателей волевой регуляции, обеспечивающих успешность процесса адаптации. Проблема адаптации напрямую связана с проблемой психического благополучия личности, являющейся одной из фундаментальных в современной психологической науке. Анализ недавних исследований позволил определить адаптацию - как уникальный для каждой личности процесс, результат которого зависит от индивидуально-психологических характеристик, объективных и субъективных факторов, а генеральной целью выступает реализация внутреннего потенциала в конкретных жизненных условиях [6; 8].

Исследование особенностей волевой регуляции и адаптационной готовности иностранных студентов необходимы для разработки средств оперативной помощи и построения системы социально-психологической поддержки и сопровождения в ситуации значительных социальных и жизненных изменений, в которых происходят активные преобразования динамических характеристик личности [8].

\section{Прочедура и методы}

Участники исследования. В исследовании приняли участие 250 иностранных студентов Пензенского государственного университета (этническая общность - арабы; возрастная структура респондентов: от 17 до 24 лет, средний возраст - 20,1; гендерный состав респондентов: муж. $-\mathrm{n}=125$, жен. $-\mathrm{n}=125)$.

Методики. Для достижения цели эмпирического исследования был разработан опросный лист, включающий: «Вопросник для выявления выраженности самоконтроля в эмоциональной сфере, деятельности и поведении» (Г.С. Никифоров и др.); «Шкала контроля за действием» (Ю. Куль); «Формализованная модификация методики самооценки (СО)» (Дембо-Рубинштейн); «Тест смысложизненных ориентаций» (Д.А. Леонтьев); вопросы, касающиеся ряда демографических характеристик респондентов и оценки уровня удовлетворенности условиями пребывания в инокультурной среде (климат, культура, питание, условия проживания, обучения, досуг и т.д.).

\section{Методы}

Для выявления связей удовлетворенности иностранными студентами условиями пребывания в инокультурной среде с самоконтролем, смысложизненными ориентациями, самооценкой волевых качеств, применялся корреляционный анализ (коэффициент ранговой корреляции Спирмена).

Статистическая обработка полученных данных проводилась при помощи программы SPSS Statistics v. 23.

\section{Результаты и их обсужкение}

Полученные данные корреляционного анализа свидетельствуют о наличии 5 положительных корреляционных связей удовлетворенности условиями жизни в инокультурной среде и контроля за действием при планировании.

Показатель шкалы контроля за действием при планировании положительно взаимосвязан с удовлетворенностью иностранных студентов культурой страны пребывания $(0,190)$, условиями обучения $(0,329)$, качеством питания $(0,198)$, студенческой жизнью $(0,316)$ и образом жизни в целом $(0,277)$.

Наличие положительных связей свидетельствует в пользу того, что иностранные студенты, обладающие более продуктивной стратегией волевой регуляции (ОДдиспозиция), осуществляющие регуляцию намеренного действия непроизвольно, в большей мере удовлетворены условиями обучения, студенческой жизнью, образом жизни в целом, качеством питания и национальной культурой страны пребывания.

Также корреляционный анализ показал 11 положительных взаимосвязей удовлетворенности условиями жизни и самоконтроля в эмоциональной сфере, деятельности и поведении. 
Эмоциональный самоконтроль иностранных студентов связан с удовлетворенностью качеством питания $(0,146)$, студенческой жизнью $(0,133)$ и образом жизни в целом $(0,254)$. Данные связи свидетельствуют о том, что при удовлетворенности указанными сторонами жизни эмоциональный самоконтроль иностранных студентов возрастает. И наоборот, снижение удовлетворенности образом жизни в целом, качеством питания и студенческой жизнью будет провоцировать снижение эмоционального самоконтроля у иностранных студентов.

Поведенческий самоконтроль иностранных студентов взаимосвязан с условиями обучения $(0,142)$ и образом жизни в целом $(0,173)$. Другими словами, самоконтроль в деятельности студентов возрастает с ростом их удовлетворенности образом жизни в целом и условиями обучения в частности.

Склонность к социальному самоконтролю иностранных студентов взаимосвязана с большинством сторон удовлетворенности жизни. Иностранные студенты проявляют более высокий социальный самоконтроль при удовлетворенности образом жизни в целом $(0,302)$, культурой $(0,286)$, условиями обучения $(0,284)$, студенческой жизнью $(0,253)$, климатом $(0,168)$ и качеством питания $(0,137)$.

Таблица 1 / Table 1

Значимые корреляционные связи между удовлетворенностью условиями жизни и самоконтролем в эмоциональной сфере, деятельности и поведении $(\mathrm{N}=250)$

\begin{tabular}{|l|c|c|c|}
\multirow{2}{*}{$\begin{array}{l}\text { Показатели } \\
\text { удовлетворенности }\end{array}$} & \multicolumn{3}{|c|}{ Показатели самоконтроля } \\
\cline { 2 - 4 } Уд1 & 0,060 & $-0,022$ & $0,168^{* *}$ \\
\hline Уд2 & 0,079 & 0,006 & $0,286^{* *}$ \\
\hline Уд3 & 0,014 & $0,142^{*}$ & $0,284^{* *}$ \\
\hline Уд4 & $0,146^{*}$ & 0,100 & $0,137^{*}$ \\
\hline Уд5 & $0,133^{*}$ & 0,001 & $0,253^{* *}$ \\
\hline Уд6 & 0,021 & 0,100 & 0,050 \\
\hline Уд7 & 0,106 & 0,011 & 0,040 \\
\hline Уд8 & $0,254^{* *}$ & $0,173^{* *}$ & $0,302^{* *}$ \\
\hline
\end{tabular}

Примечание: * - уровень статистической значимости 0,05; ** - уровень статистической значимости 0,01; ЭСК - эмоциональный самоконтроль, ПСК - поведенческий самоконтроль, ССК- социальный самоконтроль.

Таким образом, мы можем констатировать, что самоконтроль в эмоциональной сфере, деятельности и поведении иностранных студентов в первую очередь взаимосвязан с удовлетворенностью образом жизни в целом. Удовлетворенность условиями жизни иностранных студентов, в свою очередь, в большей степени свя- зана с их склонностью к социальному самоконтролю.

Оценка корреляционных связей удовлетворенности условиями жизни и смысложизненными ориентациями показала наличие 21 положительной связи. Обнаружены устойчивые положительные связи между наличием целей в будущем, придающих иностранным студентам осмысленность жизни, направленность и временную перспективу, и удовлетворенность образом жизни в целом $(0,235)$.

Таким образом, в выборке иностранных студентов установлена устойчивая взаимосвязь осмысленности жизненных целей с удовлетворенностью жизнью в целом.

Рассматривая корреляционные связи между осмысленностью эмоциональной насыщенности жизни, ее процессом и удовлетворенностью условиями жизни, обнаружены устойчивые связи с такими сторонами удовлетворенности, как удовлетворенность климатом $(0,172)$, культурой $(0,163)$, качеством питания $(0,176)$, студенческой жизнью $(0,177)$ и образом жизни в целом. Результативность жизни, ощущение продуктивности и осмысленности пройденного этапа жизни у иностранных студентов возрастает при удовлетворенности климатом $(0,325)$, качеством питания $(0,209)$ и образом жизни в целом $(0,267)$.

Вместе с представлениями иностранных студентов о себе как о личности, имеющей свободу выбора и волю к построению жизни в соответствии с поставленными целями, отмечается рост уровня удовлетворенности культурой принимающей страны $(0,150)$, процессом организации студенческой жизни $(0,127)$ и образа жизни в целом $(0,247)$.

Убежденность иностранных студентов в способности контролировать свою жизнь, принимать решения и воплощать их в жизнь определяется ее связями с удовлетворенностью климатом $(0,244)$, качеством питания $(0,198)$ и образа жизни в целом $(0,225)$. С другой стороны, осознание ими иллюзорности жизненного выбора, бессмысленности планов на будущее связано со снижением указанных сторон удовлетворенности условиями жизни.

Обобщая установленные связи, заключим, что удовлетворенность условиями жизни в инокультурной среде в большей степени связана с осмысленностью процесса жизни, ее результатами и ее управляемостью.

В свою очередь, смысложизненные ориентации иностранных студентов определены, прежде всего, удовлетворенностью образом жизни в целом.

При анализе показателей самооценки волевых ка- 
Значимые корреляционные связи между удовлетворенностью условиями жизни и смысложизненными ориентациями $(\mathrm{N}=250)$

\begin{tabular}{|c|c|c|c|c|c|c|}
\hline \multirow{2}{*}{ Показатели Удовлетворенности } & \multicolumn{5}{|c|}{ Показатели смысложизненных ориентаций } \\
\cline { 2 - 7 } & СЖ0-общий & СЖ0-цели & СЖ0-процесс & СЖ0-результат & СЖ0-ЛК_я & СЖ0-ЛК_жизнь \\
\hline Уд1 & $0,211^{* *}$ & 0,110 & $0,172^{* *}$ & $0,325^{* *}$ & 0,118 & $0,244^{* *}$ \\
\hline Уд2 & 0,097 & 0,034 & $0,163^{* *}$ & 0,116 & $0,150^{*}$ & 0,097 \\
\hline Уд3 & 0,021 & 0,040 & 0,055 & 0,099 & 0,051 & $-0,043$ \\
\hline Уд4 & $0,204^{* *}$ & $0,168^{* *}$ & $0,176^{* *}$ & $0,209^{* *}$ & 0,074 & $0,198^{* *}$ \\
\hline Уд5 & $0,127^{*}$ & 0,103 & $0,177^{* *}$ & 0,107 & $0,127^{*}$ & 0,053 \\
\hline Уд6 & 0,044 & 0,110 & $-0,005$ & $-0,066$ & 0,037 & 0,008 \\
\hline Уд7 & 0,036 & $-0,034$ & 0,077 & 0,040 & $-0,072$ & 0,048 \\
\hline Уд8 & $0,279^{* *}$ & $0,235^{* *}$ & $0,191^{* *}$ & $0,267^{* *}$ & $0,247^{* *}$ & $0,225^{* *}$ \\
\hline
\end{tabular}

Примечание: * - уровень статистической значимости 0,05; ** - уровень статистической значимости 0,01; СЖО смысложизненные ориентации.

Таблица 3 / Table 3

Значимые корреляционные связи между удовлетворенностью условиями жизни и самооценки волевых качеств $(\mathrm{N}=250)$

\begin{tabular}{|c|c|c|c|c|c|c|c|c|}
\hline \multirow{2}{*}{ Показатели самооценки волевых качеств } & \multicolumn{8}{|c|}{ Показатели удовлетворенности условиями жизни } \\
\hline & Уд1 & Уд2 & УдЗ & Уд4 & Уд5 & Уд6 & Уд7 & Уд8 \\
\hline BK1 & $-0,014$ & $0,140^{*}$ & 0,088 & 0,092 & $0,150^{*}$ & $0,192^{* *}$ & $-0,030$ & $0,162^{*}$ \\
\hline BK2 & $0,138^{*}$ & 0,016 & $-0,028$ & 0,008 & $-0,115$ & $-0,044$ & 0,078 & $0,174^{* *}$ \\
\hline BK3 & $-0,028$ & 0,092 & 0,040 & 0,076 & 0,122 & 0,026 & $-0,125^{*}$ & $0,175^{* *}$ \\
\hline BK4 & $-0,024$ & 0,033 & $-0,073$ & 0,121 & $0,187^{* *}$ & $0,263^{* *}$ & $-0,024$ & $0,173^{* *}$ \\
\hline BK5 & 0,050 & $0,206^{* *}$ & $0,429^{* *}$ & 0,070 & $0,147^{*}$ & 0,102 & $0,150^{*}$ & $0,180^{* *}$ \\
\hline BK6 & 0,075 & $0,202^{* *}$ & 0,097 & $-0,004$ & 0,023 & 0,098 & 0,040 & 0,028 \\
\hline BK7 & $0,168^{* *}$ & 0,102 & $0,274^{* *}$ & $0,142^{*}$ & $0,157^{*}$ & $-0,003$ & $-0,069$ & $-0,007$ \\
\hline BK8 & 0,026 & 0,120 & $0,160^{*}$ & $0,134^{*}$ & $0,201^{* *}$ & 0,109 & $-0,023$ & $0,225^{* *}$ \\
\hline BK9 & $-0,016$ & 0,120 & 0,044 & $-0,013$ & 0,050 & 0,013 & $-0,064$ & $0,129^{*}$ \\
\hline BK10 & $-0,099$ & 0,018 & $0,168^{* *}$ & 0,074 & $-0,030$ & $-0,006$ & $-0,068$ & $-0,023$ \\
\hline BK11 & $-0,066$ & 0,089 & $0,137^{*}$ & 0,018 & $0,150^{*}$ & 0,097 & $-0,046$ & $0,240^{* *}$ \\
\hline BK12 & 0,012 & $0,156^{*}$ & 0,121 & 0,080 & $0,274^{* *}$ & $0,282^{* *}$ & 0,044 & $0,301^{* *}$ \\
\hline BK13 & $-0,085$ & $-0,096$ & 0,107 & $0,155^{*}$ & 0,124 & 0,107 & 0,061 & 0,093 \\
\hline BK14 & $0,143^{*}$ & $0,230^{* *}$ & $0,174^{* *}$ & 0,086 & 0,120 & $0,176^{* *}$ & $-0,023$ & $0,183^{* *}$ \\
\hline BK15 & $-0,002$ & $0,169^{* *}$ & $0,157^{*}$ & 0,086 & $0,164^{* *}$ & 0,089 & $-0,135^{*}$ & 0,094 \\
\hline BK 16 & $-0,104$ & $-0,057$ & 0,057 & 0,023 & $-0,016$ & 0,017 & $-0,100$ & $-0,015$ \\
\hline BK17 & 0,040 & $-0,043$ & $-0,039$ & 0,108 & 0,118 & 0,036 & $-0,093$ & 0,100 \\
\hline BK18 & 0,058 & $0,184^{* *}$ & $0,128^{*}$ & 0,116 & $0,138^{*}$ & $0,150^{*}$ & $-0,073$ & $0,182^{* *}$ \\
\hline BK19 & 0,110 & 0,076 & 0,067 & 0,094 & $0,140^{*}$ & 0,077 & $-0,118$ & $0,128^{*}$ \\
\hline BK20 & 0,025 & 0,087 & 0,114 & $0,146^{*}$ & $0,165^{* *}$ & $-0,041$ & $-0,117$ & $-0,019$ \\
\hline
\end{tabular}

Примечание: * - уровень статистической значимости 0,05; ** - уровень статистической значимости 0,01; ВК1 - «от-

ветственность», ВК2 - «дисциплинированность», ВК3 - «целеустремленность», ВК4 - «принципиальность», ВК5

- «обязательность», ВК6 - «настойчивость», ВК7 - «решительность», ВК8 - «воля», ВК9 - «инициативность», ВК10 «Выдержанность», ВК11 - самостоятельность», ВК12 - энергичность», ВК13 - «терпеливость», ВК14 - «упорство», ВК15 - «смелость», ВК16 - «спокойность», ВК17 - «деловитость», ВК18 - «уверенность», ВК19 - «организованность», ВК20 - «внимательность». 
честв и удовлетворенности условиями жизни в инокультурной среде установлены многочисленные взаимосвязи $(p<0,01)$. Рассмотрим наиболее значимые корреляционные связи.

Удовлетворенность климатом положительно связана с такими волевыми качествами как «решительность» $(0,168)$, «упорство» $(0,143)$ и «дисциплинированность» $(0,138)$ иностранных студентов.

Удовлетворенность культурой наиболее тесно коррелирует с волевыми качествами «смелость» $(0,230)$, «обязательность» $(0,206)$, «настойчивость» $(0,202)$, «уверенность» $(0,184)$ и др.

Удовлетворенность условиями обучения у иностранных студентов возрастает при высоком уровне самооценки «обязательности» $(0,429)$, «решительности» $(0,274)$, «упорства» $(0,174)$, «выдержанности» и др.

Удовлетворенность качеством питания (национальной русской кухней) иностранных студентов связана с такими личностными качествами, как «терпеливость» $(0,155)$, «внимательность» $(0,146)$, «решительность» $(0,142)$.

Удовлетворенность студенческой жизнью связана в большей степени с «энергичностью» $(0,274)$ и «волей» $(0,201)$.

Удовлетворенность условиями проживания согласуется с высокой самооценкой «энергичности» $(0,282)$, «принципиальности» $(0,263)$, «ответственности» $(0,192)$.

Иностранные студенты в большей степени удовлетворены своим свободным временем, при условии высокой самооценки «обязательности» $(0,150)$ и низкой «смелости» $(-0,135)$ и «целеустремленности» $(-0,125)$.

Оценка условия «удовлетворенность образом жизни в целом» у иностранных студентов возрастает при высо- ких показателях самооценки таких качеств, как «терпеливость» $(0,301)$, «энергичность» $(0,240)$ и др.

Таким образом было установлено, что студенты с более высоким уровнем удовлетворенности условиями жизни, так же наиболее высоко оценивают собственные волевые качества.

\section{Зак^ючение}

Можно заключить, что адаптации студентов к инокультурной среде свойственны характеристики как процесса приспособления (социально-психологического феномена), так и особого состояния личности, отражающего особенности волевой регуляции.

Наиболее тесная взаимосвязь была обнаружена по показателям выраженности социального самоконтроля с удовлетворенностью условиями жизни. У иностранных студентов удовлетворенность образом жизни в целом, и студенческой жизнью в частности, связана с большинством сторон самооценки волевых качеств: «терпеливость», «энергичность», «воля», «упорство», «уверенность», «обязательность», «целеустремленность», «дисциплинированность», «принципиальность», «ответственность», «инициативность», «организованность». Данная связь указывает на зависимость удовлетворенности условиями жизни (т.е. успешности адаптации к инокультурной среде) от уровня развития волевых качеств личности.

Кроме того, иностранные студенты, обладающие более продуктивной стратегией волевой регуляции (ОДдиспозиция), осуществляющие регуляцию намеренного действия непроизвольно, более удовлетворены условиями обучения и образом жизни в целом.

Таким образом, гипотеза о взаимосвязи показателей волевой регуляции и успешности протекания процесса адаптации к новой социокультурной и образовательной среде подтвердилась.

\section{ЛИТЕРАТУРА}

1. Асмолов А.Г. Психология личности: культурно-историческое понимание развития человека. - М.: Смысл, 2007. - 528 с.

2. Иванников В.А., Гусев А.Н., Барабанов Д.Д., Эйдман Е.В. Осмысленность жизни и ориентация на действие как предикторы самооценок волевых качеств // Вестник московского университета. 2020. №2. С. 3 - 25.

3. Иванников В.А., Шляпников В.Н. Особенности волевой регуляции у представителей разных этнокультурных групп // Экспериментальная психология. 2019. T. 12. №. 1. C. 70 - 84. D0I:10.17759/exppsy.2019120106

4. Иванников В.А., Барабанов Д.Д., Монроз А.В., Шляпников В.Н., Эйдман Е.В. Место понятия «воля» в современной психологии // Вопросы психологии. 2014. № 2. C. 15-23.

5. Быков А.В., Шульга Т.И. Эмоционально-волевая регуляция как вид психологической готовности человека к обучению. Монография. -М. Изд.: Мгоу, 2012. $-142 C$.

6. Константинов, В.В. Социально-психологическая адаптация мигрантов: теория и эмпирические исследования. - М.: Перо, 2018. - 236 с. 
7. Леонтьев Д.А. Развитие личности в норме и в затрудненных условиях: вызовы и ресурсы // Культурно-историческая психология. 2014. № 3. С. 97-106.

8. Шамионов Р.М. Отношение к изменениям и толерантность к неопределенности как предикторы адаптивности и адаптационной готовности // Российский психологический журнал. - 2017. - Т. 14, № 2. - С. 90-104.

9. Шульга Т.И. Некоторые итоги развития проблемы воли и волевой регуляции в исследованиях научной школы // Вестник Московского государственного областного университета. Серия: Психологические науки. 2020. № 1. C. 8-21. DOI: 10.18384/2310-7235-2020-1-8-21

10. Kuhl J. Who controls whom when «l control myself»? // Psychological-Inquiry. 1996; Vol. 7 (1). P. 61-68.

( К Куц Анна Вячеславовна (kuts_a.v@mail.ru), Воробьева Кристина Игоревна (v.i.e.3@mail.ru).

Журнал «Современная наука: актуальные проблемы теории и практики»

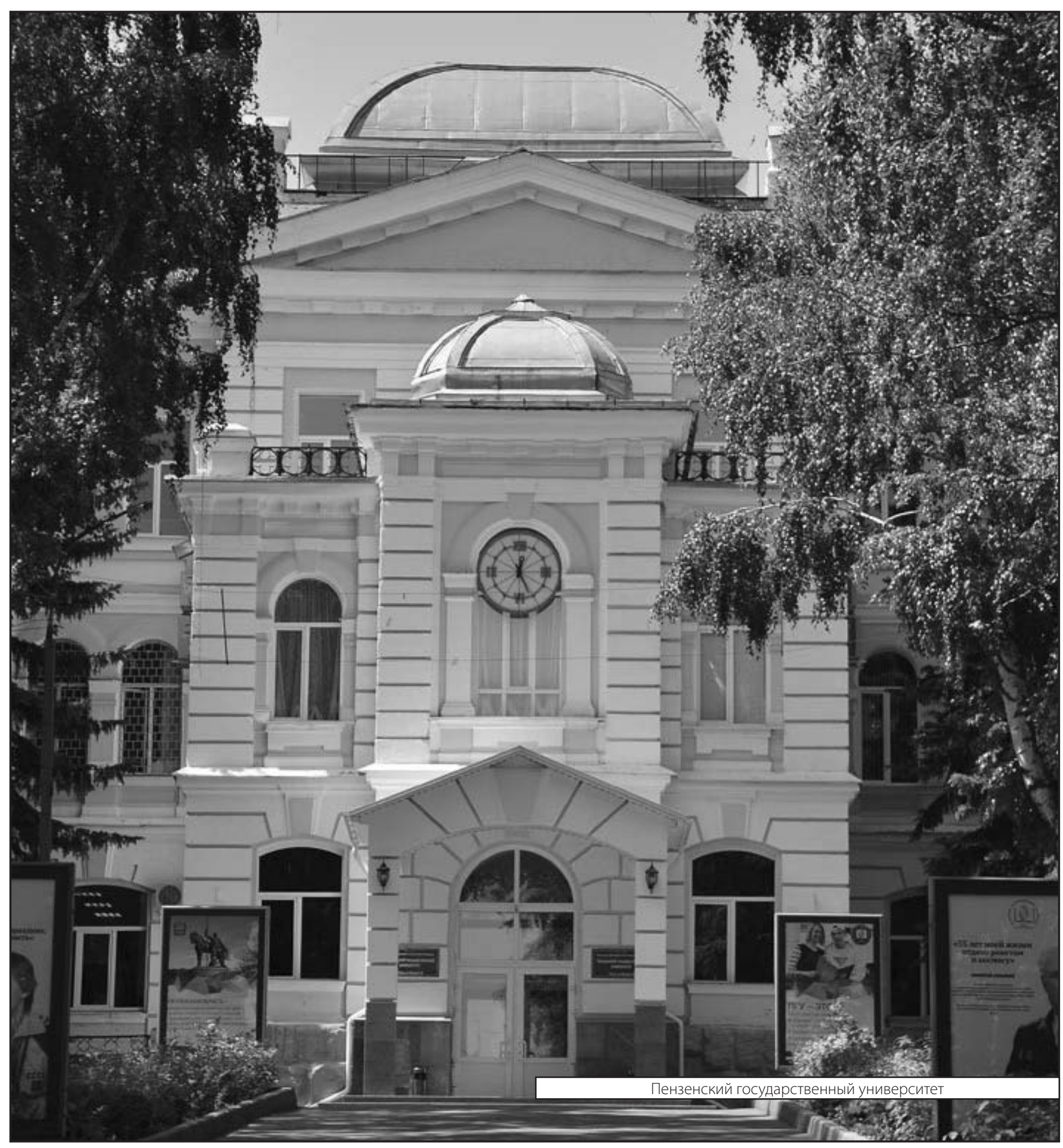

